\title{
The Role of Synthetic Superhydrophobic Surfaces in Construction Materials
}

\author{
Ali Raza Shaikh*, Jian Qu and Dmitrii Grachev \\ School of Energy and Power Engineering, Department of Power Engineering and Engineering Thermophysics, Jiangsu University, Zhenjiang, Jiangsu Province, \\ 212013, China
}

*Corresponding author: Ali Raza Shaikh, School of Energy and Power Engineering, Department of Power Engineering and Engineering Thermophysics, Jiangsu University, Zhenjiang, Jiangsu Province, 212013, China.

Received Date: June 26, 2020

Published Date: July 17, 2020

\begin{abstract}
The bio-inspired superhydrophobic surfaces have the capability to repel the water and this characteristic has great significance in industries. Superhydrophobic surfaces are playing a vital role in the variety of applications in different fields due to their chemical and physical properties. In this paper, the role of synthetic superhydrophobic surfaces in construction materials was discussed in detail. The fabrication techniques of superhydrophobic surfaces, their properties, and their applications were also reviewed. There are a lot of construction materials that are used in buildings, roads, railways, airports, bridges, dams, and water tanks. Many researchers have fabricated superhydrophobic coatings on different concrete surfaces and they found it very helpful to overcome the problems. This review article presented the three major problems and their solutions in construction materials which are waterproofing, anticorrosion, and anti-icing. In the meantime, the future perspective was also mentioned.
\end{abstract}

Keywords: Superhydrophobic surfaces; Construction materials; Waterproofing; Anticorrosion; Anti-icing

\section{Introduction}

The super hydrophobicity was inspired by nature such as lotus leaves [1], poplar leaves [2], fish scale [3], butterfly wings [4], water strider legs [5], peanut leaves [6] and red rose petal [7] (Figure 1). These bio-inspired superhydrophobic surfaces have the ability to repel the water because the water contact angle is greater than $150^{\circ}$ and contact angle hysteresis less than $10^{\circ}$. Many scientists have done research studies on the fabrication of artificial superhydrophobic surfaces [8-14]. The researchers found that these coatings have tremendous properties that can be used in different applications for various materials and the construction materials are one of them [15-17]. Different construction materials are used to build roads, buildings, bridges, dams, water tanks, airports, and railways. The waterproofing is one of the important elements in concrete structures to make them durable and robust by preventing them from moisture and leaks. The steel-reinforced concrete is almost used in everything either it's a building or bridge. However, the steel corrosion is a major problem and it also damages the concrete itself. Besides, the icing on the concrete pavement, roads, bridges, and airplane wings is greatly increasing injury and mortality rates. The superhydrophobic coatings are the most promising candidates to overcome these problems [18]. This study aims to provide a comprehensive review of the problems faced in construction materials and their possible solutions through using superhydrophobic surfaces and provide a reference for other researchers (Figure 1).

\section{Waterproofing}

In all types of structures, there are some common problems such as leakage and moisture. For buildings, the water is considered an enormous enemy. The water affects the structure very dangerously and it can cause many accidents due to lake of durability and robustness of the structure. Up till now, many researchers have fabricated the superhydrophobic concrete surfaces for 
waterproofing [20]. Horgnies et al. [21] prepared the Ultra-HighPerformance Concrete (UHPC) by applying micro/nano-pillar moulds of polydimethylsiloxane (PDMS). The water contact angle of $164^{\circ}$ and the contact angle hysteresis of $2.5^{\circ}$ was achieved. The as prepared superhydrophobic surface on concrete has prodigious self-cleaning and water repellent properties. Recently, she et al. [22] fabricated a durable superhydrophobic concrete by a nanohybrid method. This water-resistant concrete has outstanding mechanical resistance of surface due to nano/micro two hierarchical structures and effects of nano silica. The contact angle was greater than $150^{\circ}$. This method was simple and low cost and it can be used for larger surface area applications (Figure 2).

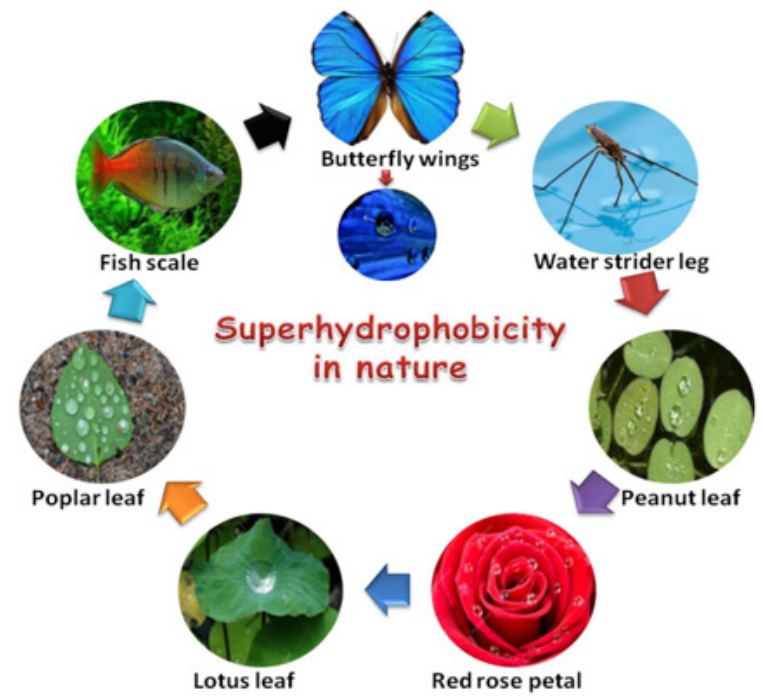

Figure 1: Existence of superhydrophobic surfaces in nature [19].

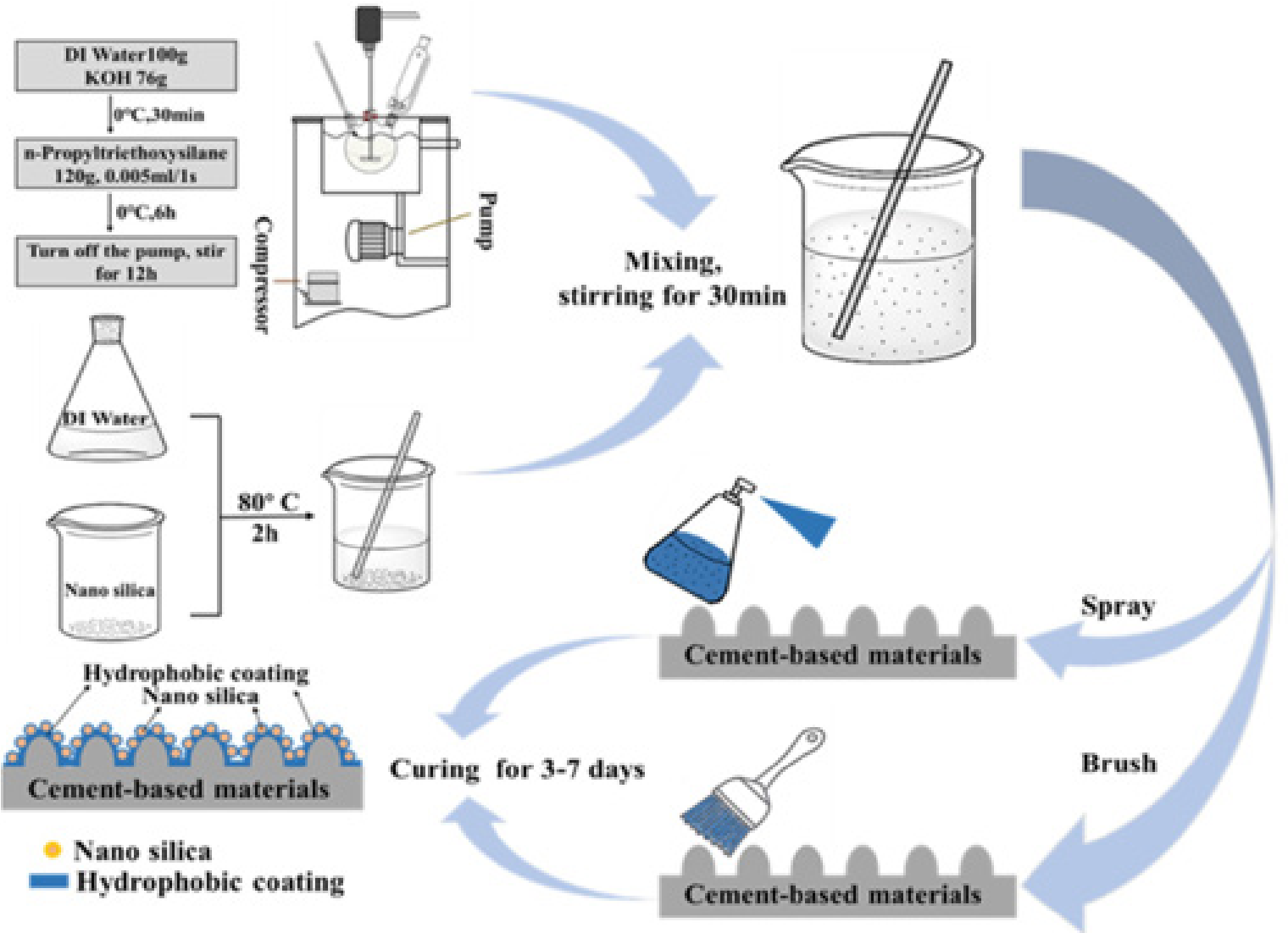

Figure 2: The schematic diagram of the whole process and its application [22]. 
Li et al. [23] prepared fluorine-free and environmentally friendly carbon-based superhydrophobic coating on the concrete surface through adding B-doped carbon particle (BCP) aggregate and metakaolin (MK) in polyvinyl alcohol (PVA) solution (Figure 3 ). The surface exhibited excellent superhydrophobic properties with a water contact angle of $156^{\circ}$. This inexpensive method was durable and it can be used for waterproofing and self-cleaning in buildings (Figure 3).

Recently, Yongjuan et al. [24] prepared a superhydrophobic coating on the concrete surface via the $\mathrm{GO} /$ silane composite process (Figure 4). With excellent roll-off properties, the water contact was $165.5^{\circ}$. The surface has good waterproof properties (Figure 4).

Dong et al. [25] fabricated a superhydrophobic surface on a concrete surface with excellent self-cleaning, mechanical strength, sound adsorption, and heat insulation properties. Through a simple two-step process of pore-forming and novel bulk modification, they successfully achieved a water contact angle of $166^{\circ}$. The surface maintained superhydrophobicity in harsh environments such as heat treatment, chemical erosion, and mechanic grinding. The fabricated concrete surface can be used in many industrial applications.

\section{Anticorrosion}

There are different metal substrates such as steel, copper, aluminum, cast iron, brass, and bronze are used in the construction of buildings, bridges, railways, etc. The corrosion is a very big problem for these metals. Many methods of synthetic superhydrophobic surfaces have been employed to achieve anticorrosive properties [26,27]. Zhang et al. [28] manufactured a superhydrophobic surface on the S45C steel substrate. The manufactured superhydrophobic surface exhibited excellent anticorrosion property. The surface showed the contact angle of $158 \pm 2^{\circ}$ and a sliding angle of $3 \pm 1^{\circ}$ (Figure 5). The surface also exhibited outstanding chemical stability and mechanical robustness which enabled to use of this method in industrial applications (Figure 5).

they successfully achieved a water contact angle of $166^{\circ}$. The

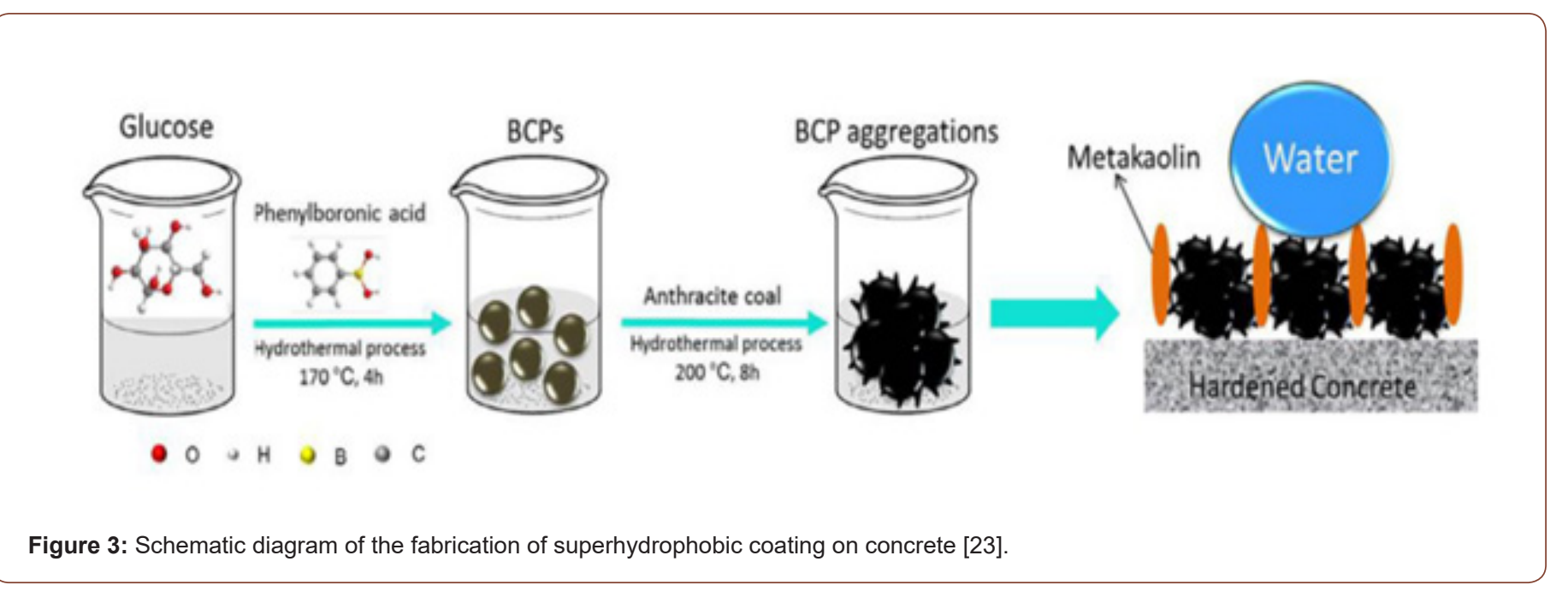

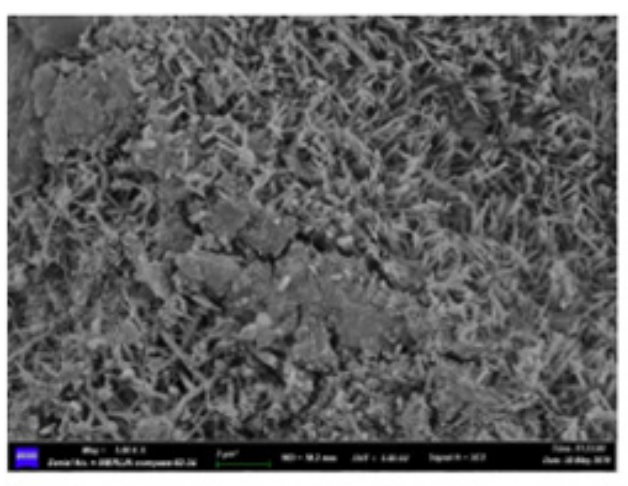

(a)

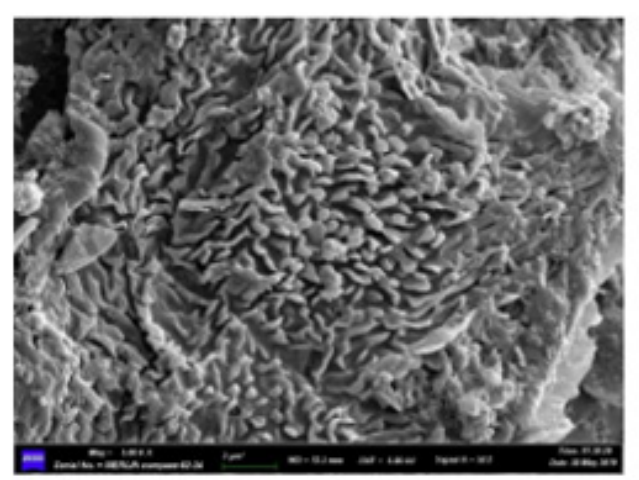

(b)

Figure 4: SEM snapshots of concrete surface (a) without processed through GO/silane composite (b) processed through GO/silane composite [24]. 


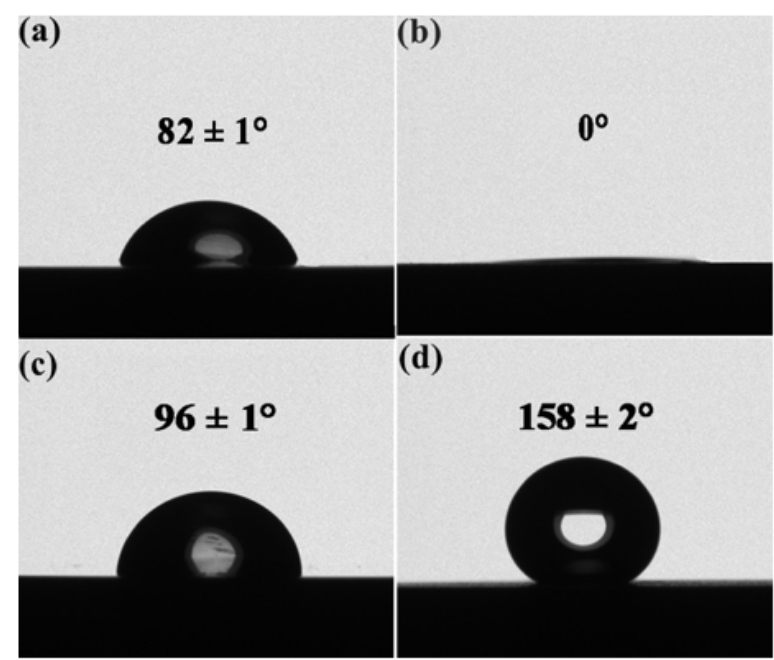

Figure 5: Contact angles of (a) bare steel (b) textured steel (c) modified bare steel (d) modified textured steel [28].

The concrete is one of the building materials widely used in both architecture and marine engineering [29,30]. The steel inside the concrete is inevitably affected by corrosion [31]. Severe corrosion can damage the internal components of concrete, which may greatly shorten the service life of the concrete and increase potential safety risks [32-34]. Lei et al. [35] fabricated superhydrophobic concrete with a water contact angle of $159^{\circ}$ and a sliding angle of $5^{\circ}$. The fabricated superhydrophobic concrete exhibited excellent anticorrosion and stable mechanical properties. The method was non-toxic and environment friendly. Wang et al. [36] prepared a superhydrophobic steel surface through combining hydrogen peroxide and acid (hydrochloric acid or nitric acid) to obtain a layered structure on steel, and then performed surface modification treatment. The as-prepared superhydrophobic surface showed outstanding properties of anticorrosion, anti-icing, mechanically robust, and UV-durability. Nine et al. [37] manufactured robust superhydrophobic graphene-based composite coatings that can be applied to a variety of materials such as metals, papers, and glasses through using spray, dipping, and brush painting on the surfaces. The water contact angle was greater than $172^{\circ}$. The surface exhibited outstanding anticorrosion and self-cleaning properties. Meanwhile, it was found that the surface can perform very well in harsh environments and it can also protect reactive surfaces as a chemical shield. Lately, Yin et al. [38] fabricated superhydrophobic coating on the concrete surface through biomimetic mineralization (M-concrete) followed by low surface energy silane modification (S-concrete). After the modification of silane, the superhydrophobic surface exhibited excellent anticorrosion property. The contact angle of the surface was found to be $156 \pm 3^{\circ}$ (Figure 6). The fabricated superhydrophobic concrete surface has good stability (Figure 6).

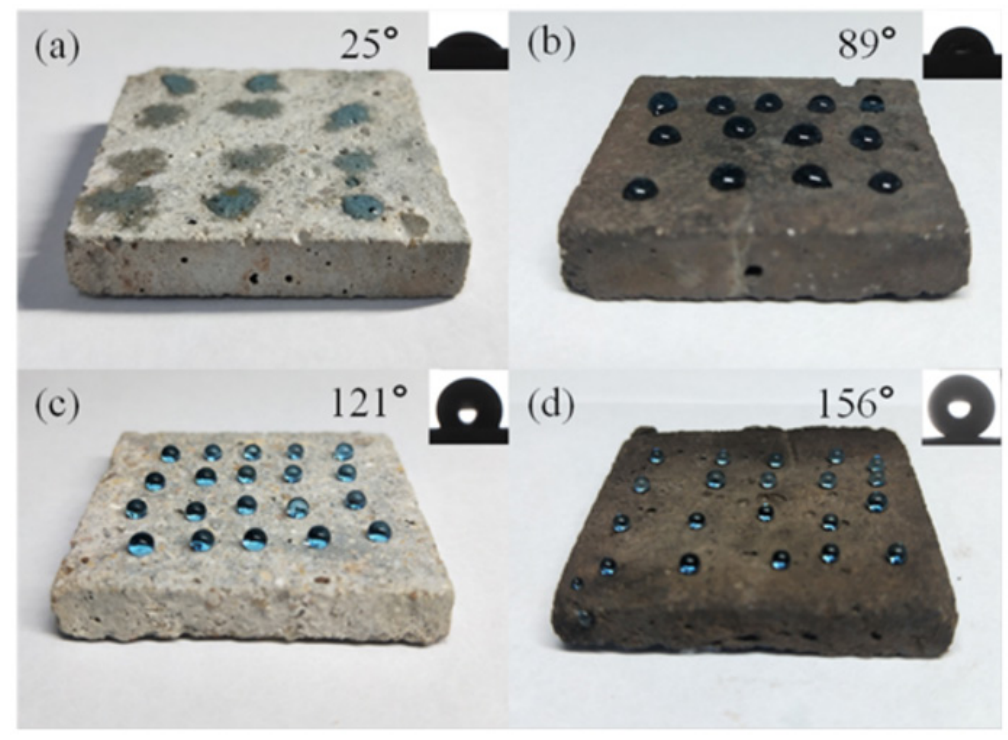

Figure 6: The digital snapshots of droplets of water on (a) plain concrete (b) M-concrete (mineralization layer) (c) S-concrete (modified by silane) (d) S-M concrete (silane hydrophobic coating). The values of contact angles are shown [38]. 


\section{Anti-icing}

During the winter season, the ice formation on roads, signboards, airplane wings, bridges, and electrical wires caused many accidents such as slippery roads, cracks in concrete structures, and flight delays. Due to these reasons, there are a lot of economic losses every year [39]. The superhydrophobic surfaces have gained enormous attention from many researchers and several fabrication techniques are employed to overcome these problems [40,41]. Recently, Zhao et al. [42] fabricated a superhydrophobic coating on concrete through a two-step spray method (Figure 7). The method was found to have the properties of anti-icing and good durability (Figure 7).

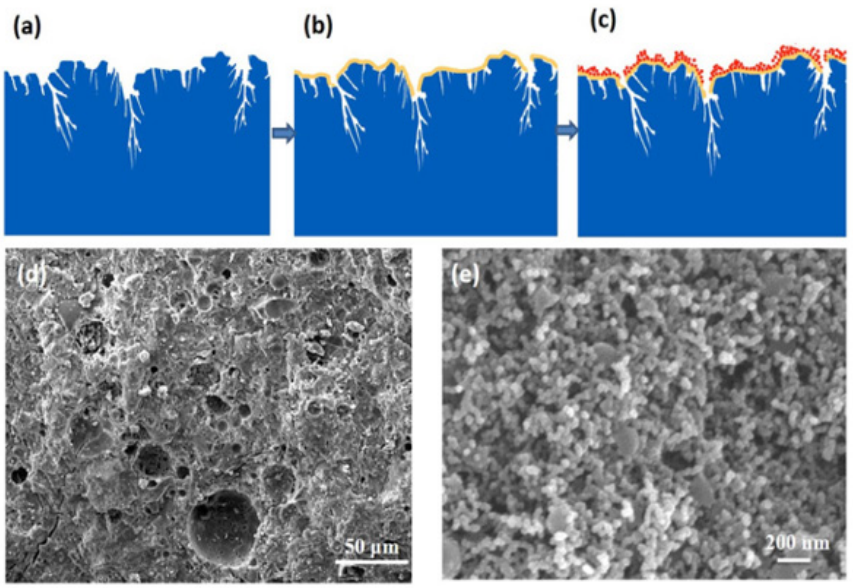

Figure 7: (a-c) Schematic diagram of the formation of superhydrophobic coating (d) SEM snapshots of the pure concrete surface and (e) after the fabrication of superhydrophobic coating on concrete [42].

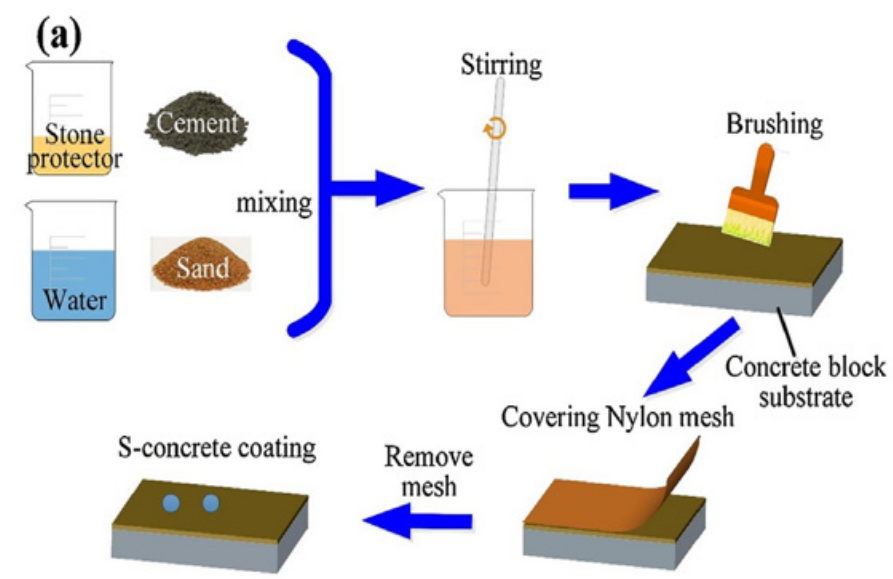

Figure 8: Schematic diagram of the whole fabrication process of S-concrete [43].

Song et al. [43] prepared simple, inexpensive, non-fluorinated, and robust superhydrophobic concrete (S-concrete) which has excellent properties such as anti-icing, a low deicing force, and anticorrosion. The process included several raw materials such as sand, cement, nylon mesh, and commercial water-based stone protector (Figure 8). The water contact angle was $160 \pm 1^{\circ}$ and sliding was $6.5 \pm 0.5^{\circ}$. This method can be very useful on a large scale for anti-icing and anticorrosion and it can be applied to concretes which are used in buildings, bridges, roads, etc. (Figure 8).

Arabzadeh et al. [44] manufactured superhydrophobic coating on concrete surfaces for anti-icing and snow-free roadways and airport applications. For fabricating superhydrophobic surfaces on concrete, the layer-by-layer (LBL) method was used with polytetrafluoroethylene (PTFE). The contact angle was greater than $150^{\circ}$. The results showed that the superhydrophobic concrete surface has outstanding super-water-repellent and anti-icing properties. Zhu et al. [45] developed a superhydrophobic cement concrete surface that has excellent anti-ice rain properties under $-12{ }^{\circ} \mathrm{C}$. Moreover, the as-prepared superhydrophobic cement concrete surface has good heat-reflective properties. This method can be applied in the applications of building roofs and outside walls for reducing air-conditioning energy consumption in hot weather. Ramachandran et al. [46] fabricated superhydrophobic concrete with micro/nanostructured anti-icing property. The icephobic concrete surface repelled water droplets at $-5{ }^{\circ} \mathrm{C}$. The 
performance of icephobic concrete can be improved by adjusting the fiber content of polyvinyl alcohol and sand.

\section{Conclusion and Future Perspective}

The super hydrophobicity was found in nature several years ago i.e. in plants and animals. Later on, the superhydrophobic surfaces fascinated the attention of many researchers because of their huge chemical and physical properties such as self-cleaning, waterproofing, anticorrosion, and anti-icing. Many scientists have fabricated synthetic superhydrophobic surfaces for different applications. The superhydrophobic surfaces are playing a very important role in the construction materials for instance in buildings, roads, railways, airports, bridges, dams, and water tanks. This review study provided a comprehensive overview of the problems that are encountered by researchers in construction materials and their remedies by using superhydrophobic surfaces. The fabrication methods of superhydrophobic coatings were also discussed. Meanwhile, the properties and applications of each method were mentioned. The three main problems and their solutions were discussed:

- Waterproofing

- Anticorrosion

- Anti-icing

The future work of superhydrophobic coatings in terms of construction materials should be to improve stability and performance which is a very big challenge nowadays. The research should also move on a larger scale of fabrication so that it can be used in the industrial and daily life applications more frequently. We should also attain cheap and eco-friendly fabrication materials.

\section{Acknowledgment}

None.

\section{Conflict of Interest}

No conflict of interest.

\section{References}

1. Cheng YT, Rodak DE (2005) Is the lotus leaf superhydrophobic. Appl Phys Lett 86: 144101.

2. Ye C, Li M, Hu J, Q Cheng Q, Jiang L, et al. (2011) Highly reflective superhydrophobic white coating inspired by poplar leaf hairs toward an effective. cool roof Energy Environ Sci 4 3364-3367.

3. Das, Sengupta S, Deka J, Rather AM, Raidongia K, et al. (2018) Synthesis of fish scale and lotus leaf mimicking, stretchable and durable multilayers. J Mater Chem A 6: 15993-16002.

4. Byun D, Hong J, Saputra, Ko JH, Lee YJ, et al. (2009) Wetting Characteristics of Insect Wing Surfaces. J Bionic Eng 6: 63-70.

5. X Gao, L Jiang (2004) Water-repellent legs of water striders. Nature 432: 36.

6. Yang S, Ju J, Qiu Y, He Y, Wang X, et al. (2014) Peanut leaf inspired multifunctional surfaces. Small 10: 294-299.

7. Feng L, Zhang Y, Xi J, Zhu Y, Wang N, et al. (2008) Petal effect: a superhydrophobic state with high adhesive force. Langmuir 24: 41144119.
8. Fürstner R, Barthlott W, Neinhuis C, Walzel P (2005) Wetting and selfcleaning properties of artificial superhydrophobic surfaces. Langmuir 21(3): 956-961.

9. Han JT, Xu X, Cho K (2005) Diverse access to artificial superhydrophobic surfaces using block copolymers. Langmuir 21: 6662-6665.

10. Feng L, Li S, Li Y, Li H, Zhang L, et al. (2002) Super-hydrophobic surfaces: from natural to artificial. Adv Mater 14: 1857-1860.

11. Luo ZZ, Zhang ZZ, Hu LT, Liu WM, Guo ZG, et al. (2008) Stable bionic superhydrophobic coating surface fabricated by a conventional curing process. Adv Mater 20: 970-974

12. Bhushan B, Jung YC (2011) Natural and biomimetic artificial surfaces for superhydrophobicity, self-cleaning, low adhesion, and drag reduction. Prog Mater Sci 56: 1-108.

13. Saji VS (2020) Wax-based Artificial Superhydrophobic Surfaces and Coatings. Colloids Surfaces A Physicochem Eng Asp 125132.

14. He J, Zhao Y, Yuan M, Hou L, Abbas A, et al. (2020) Fabrication of durable polytetrafluoroethylene superhydrophobic materials with recyclable and self-cleaning properties on various substrates. J Coatings Technol Res 1-9.

15. Manoudis PN, Tsakalof A, Karapanagiotis I, Zuburtikudis I, Panayiotou C (2009) Fabrication of super-hydrophobic surfaces for enhanced stone protection. Surf Coatings Technol 203 1322-1328.

16.Zhang BL, Liu ZA, Huang L, Song JL, Sun YW (2019) Fabrication of Superhydrophobic Surfaces on Metal Substrates by Nanosecond Laser. in: Key Eng Mater Trans Tech Publ pp. 48-53.

17. Li T, Zeng S, Ji Y, Shen B, Wang Z, et al. (2019) Water proof aerated bricks from stone powder waste through nano-TiO2 structured hydrophobic surface modification. Appl Sci 9: 2619.

18. Han B, Zhang L, Ou J (2017) Hydrophobic/Superhydrophobic Concrete. in: Smart Multifunct Concr Towar Sustain Infrastructures Springer pp. 339-357.

19. Das S, Kumar S, Samal SK, Mohanty S, Nayak SK (2018) A review on superhydrophobic polymer nanocoatings: recent development and applications. Ind Eng Chem Res 57: 2727-2745.

20. Muhammad NZ, Keyvanfar A, Majid MZA, Shafaghat A, Mirza J (2015) Waterproof performance of concrete: A critical review on implemented approaches. Constr Build Mater 101: 80-90.

21. Horgnies M, Chen JJ (2014) Superhydrophobic concrete surfaces with integrated microtexture. Cem Concr Compos 52: 81-90.

22. She W, Yang J, Hong J, Sun D, Mu S, et al. (2020) Superhydrophobic concrete with enhanced mechanical robustness: Nanohybrid composites, strengthen mechanism and durability evaluation. Constr Build Mater 247: 118563

23. Li Y, Gou L, Wang H, Wang Y, Zhang J, et al. (2019) Fluorine-free superhydrophobic carbon-based coatings on the concrete. Mater Lett 244: 31-34.

24.Geng Y, Li S, Hou D, Zhang W, Jin Z, et al. (2020) Fabrication of superhydrophobicity on foamed concrete surface by GO/silane coating. Mater Lett 265: 127423.

25. Dong B, Wang F, Abadikhah H, Hao L, Xu X, et al. (2019) Simple fabrication of concrete with remarkable self-cleaning ability, robust superhydrophobicity, tailored porosity, and highly thermal and sound insulation. ACS Appl Mater Interfaces 11(45): 42801-42807.

26. Vazirinasab E, Jafari R, Momen G (2018) Application of superhydrophobic coatings as a corrosion barrier: A review. Surf Coatings Technol 341: $40-56$.

27.Zhang D, Wang L, Qian H, Li X (2016) Superhydrophobic surfaces for corrosion protection: a review of recent progresses and future directions. J Coatings Technol Res 13: 11-29.

28. Zhang H, Yang J, Chen B, Liu C, Zhang M, et al. (2015) Fabrication of superhydrophobic textured steel surface for anti-corrosion and tribological properties. Appl Surf Sci 359: 905-910. 
29. Stewart MG, Wang X, Nguyen MN (2011) Climate change impact and risks of concrete infrastructure deterioration. Eng Struct 33: 1326-1337.

30. Fernandez RP, Pardo ML (2013) Offshore concrete structures. Ocean Eng 58: $304-316$

31. Dong B, Fang G, Liu Y, Dong P, Zhang J, et al. (2017) Monitoring reinforcement corrosion and corrosion-induced cracking by $\mathrm{X}$-ray microcomputed tomography method. Cem Concr Res 100: 311-321.

32. Maruthapandian V, Saraswathy V, Muralidharan S (2016) Development of solid state embeddable reference electrode for corrosion monitoring of steel in reinforced concrete structures. Cem Concr Compos 74: 100108.

33. Wang Y, Gong X, Wu L (2019) Prediction model of chloride diffusion in concrete considering the coupling effects of coarse aggregate and steel reinforcement exposed to marine tidal environment. Constr Build Mater 216: 40-57.

34. Shen W, Liu Y, Yan B, Wang J, He P, et al. (2017) Cement industry of China: driving force, environment impact and sustainable development. Renew Sustain Energy Rev 75: 618-628.

35. Lei L, Wang Q Xu S, Wang N, Zheng X (2020) Fabrication of superhydrophobic concrete used in marine environment with anticorrosion and stable mechanical properties. Constr Build Mater 251: 118946.

36. Wang N, Xiong D, Deng Y, Shi Y, Wang K (2015) Mechanically robust superhydrophobic steel surface with anti-icing, UV-durability, and corrosion resistance properties. ACS Appl Mater Interfaces 7(11): 62606272 .

37. Nine MJ, Cole MA, Johnson L, Tran DNH, Losic D (2015) Robust superhydrophobic graphene-based composite coatings with selfcleaning and corrosion barrier properties. ACS Appl Mater Interfaces 7(51): 28482-28493.
38. Yin B, Xu T, Hou D, Zhao E, Hua X, et al. (2020) Superhydrophobic anticorrosive coating for concrete through in-situ bionic induction and gradient mineralization. Constr Build Mater 257: 119510.

39. Cao L, Jones AK, Sikka VK, Wu J, Gao D (2009) Anti-icing superhydrophobic coatings. Langmuir 25(21): 12444-12448.

40. Fang G, Amirfazli A (2014) Understanding the anti-icing behavior of superhydrophobic surfaces. Surf Innov 2: 94-102.

41. Song J, Zhao D, Han Z, Xu W, Lu Y, et al. (2017) Super-robust superhydrophobic concrete. J Mater Chem A 5: 14542-14550.

42. Zhao Y, Liu Y, Liu Q, Guo W, Yang L, et al. (2018) Icephobicity studies of superhydrophobic coatings on concrete via spray method. Mater Lett 233: 263-266.

43. Song J, Li Y, Xu W, Liu H, Lu Y (2019) Inexpensive and non-fluorinated superhydrophobic concrete coating for anti-icing and anti-corrosion. J Colloid Interface Sci 541: 86-92.

44. Arabzadeh, Ceylan H, Kim S, Gopalakrishnan K, Sassani A (2016) Superhydrophobic coatings on asphalt concrete surfaces: toward smart solutions for winter pavement maintenance. Transp Res Rec 2551: 1017.

45. Zhu, Lv J, Chen L, Lin W, Zhang J, Yang J, Feng J (2019) Dark, heatreflective, anti-ice rain and superhydrophobic cement concrete surfaces. Constr Build Mater 220: 21-28.

46. Ramachandran R, Kozhukhova M, Sobolev K, Nosonovsky M (2016) Anti-icing superhydrophobic surfaces: Controlling entropic molecular interactions to design novel icephobic concrete. Entropy 18: 132. 